\title{
Mapping epigenetic mutations in fission yeast using whole-genome next-generation sequencing
}

\author{
Danielle V. Irvine, ${ }^{1}$ Derek B. Goto, ${ }^{1,3}$ Matthew W. Vaughn, ${ }^{1}$ Yukinobu Nakaseko, ${ }^{2}$ \\ W. Richard McCombie, ${ }^{1}$ Mitsuhiro Yanagida, ${ }^{2}$ and Rob Martienssen ${ }^{1,4}$ \\ ${ }^{1}$ Cold Spring Harbor Laboratory, Cold Spring Harbor, New York 11724, USA; ${ }^{2}$ Graduate School of Biostudies, \\ Kyoto University, Kyoto 606-8501, Japan
}

\begin{abstract}
Fission yeast is an important model for epigenetic studies due to the ease with which genetic mutants can be isolated. However, it can be difficult to complement epigenetic phenotypes with genomic libraries in order to identify the genes responsible. This is because epigenetic phenotypes are typically unstable, and can prohibit complementation if silencing cannot be reestablished. Here we have resequenced the fission yeast genome following mutagenesis to readily identify a novel mutant involved in heterochromatic silencing. Candidate genes were identified as functional single base changes linked to the mutation, which were then reconstituted in a wild-type strain to recapitulate the mutant phenotype. By this procedure we identified a weak allele of $u b c 4$, which encodes an essential E2 ubiquitin ligase, as responsible for the $s w{ }^{\star} 603$ mutant phenotype. In combination with a large collection of mutants and suppressor plasmids, next-generation genomic resequencing promises to dramatically enhance the power of yeast genetics, permitting the isolation of subtle alleles of essential genes, alleles with quantitative effects, and enhancers and suppressors of heterochromatic silencing.
\end{abstract}

[Supplemental material is available online at www.genome.org and at http:// hispaniola.cshl.edu/irvine2009a/.]

The characterization of genes involved in epigenetic silencing in Schizosaccharomyces pombe has given valuable insight into the mechanisms regulating condensed, silent chromosome domains, such as those surrounding the centromere. Many of these genes were isolated in forward genetic screens (Ekwall et al. 1999). However, due to their variegated silencing defect, these genes can be extremely difficult to clone by complementation (Ekwall et al. 1999; Kato et al. 2005; Li et al. 2005). Further, because lab strains of $S$. pombe are all derived from the same progenitor, molecular markers are rare. Instead, insertions of reporter genes have been used to map point mutations for positional cloning (Kato et al. 2005), and in forward screens by insertional mutagenesis (Li et al. 2005). Recently, it has become possible to perform reverse genetic screens using $S$. pombe knockout libraries. However, many epigenetic silencing mutants are temperature sensitive (ts) lethal point mutations (Ekwall et al. 1999), so it is likely that screening knockout libraries will miss many essential genes. Next-generation whole-genome resequencing offers an alternative to cloning epigenetic silencing mutations generated by chemical mutagenesis (Hillier et al. 2008; Mardis 2008). When this study was instigated a single lane of an Illumina (Solexa) Genome Analyzer could generate $0.5-1.0 \mathrm{~Gb}$ of sequence and enough useful sequence to get $>30$-fold coverage of $S$. pombe's $14-\mathrm{Mb}$ genome. We have used next-generation sequencing to identify a chemically induced point mutation that causes an epigenetic transcriptional silencing defect in $S$. pombe.

\section{Results}

Transcripts derived from pericentromeric repeats are silenced by two parallel mechanisms both involving histone H3K9 methyla-

\footnotetext{
${ }^{3}$ Present address: Creative Research Initiative Sousei, Hokkaido University, Sapporo 001-0021, Japan.

${ }^{4}$ Corresponding author.

E-mail martiens@cshl.edu; fax (516) 367-8369.

Article published online before print. Article and publication date are at http://www.genome.org/cgi/doi/10.1101/gr.089318.108.
}

tion: an RNAi-dependent mechanism and the Clr3 histone deacetylation pathway (Grewal and Jia 2007; Zaratiegui et al. 2007). In a genetic screen for transcriptional silencing defects, we assayed a subset of a large collection of mutagenized S. pombe strains that were temperature sensitive (ts) for growth. In each case, the growth defect could be suppressed by one or more plasmids recovered from a genomic library that had been systematically transformed into each strain (Matsumura et al. 2003; Hayashi et al. 2004; Yuasa et al. 2004). Twenty-seven ts strains were screened by reverse transcription polymerase chain reaction (RT-PCR) for repeat transcript accumulation at the nonpermissive temperature of $36^{\circ} \mathrm{C}$. One strain, designated ts603, accumulated centromeric repeat transcripts. Candidate genes from the most commonly recovered suppressor plasmids (Supplemental Table 1) were sequenced, and we identified a C-to-T base substitution within one of them, trz1(SPBC3D6.03c), that is predicted to cause a transition from an alanine to valine at amino acid 623 of the protein $(\mathrm{A} 623 \mathrm{~V})$. When the trz1-A623V allele was regenerated in an otherwise wild-type (wt) background (strain DI13; Supplemental Table 2), the strain was ts for growth on minimal media, but centromeric transcripts did not accumulate (Supplemental Fig. $1 \mathrm{~A}, \mathrm{~B})$. Moreover, the silencing defect remained but the ts phenotype was lost when the trz1-A623V allele was corrected by targeted mutagenesis (strain DI36; Supplemental Table 2). Thus trz1-A623V was responsible for the growth, but not the silencing phenotype, which was instead caused by an unmapped mutation.

Mutants in RNAi can be distinguished from other silencing defects by their specific effects on reporter gene silencing at the centromere, rather than at the mating-type locus (Zaratiegui et al. 2007). Unlike mutants in RNAi, mutants in heterochromatic modification also affect mating-type silencing and switching in a homothallic $\left(h^{90}\right)$ strain. Efficient switching can be assayed by the production of spores, which stain dark brown with iodine vapors (Moreno et al. 1991). We found that silencing of the pericentromeric otr1R::ura $4^{+}$reporter gene (Fig. 1A; Allshire et al. 1995) was relieved in the mutant strain, but to a lesser extent than 
A centromere 1

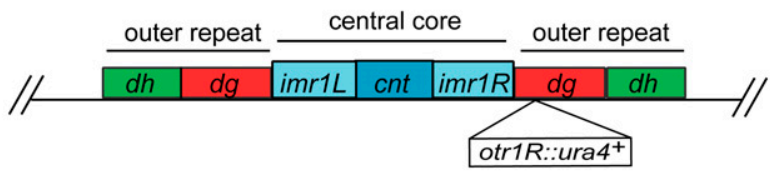

B
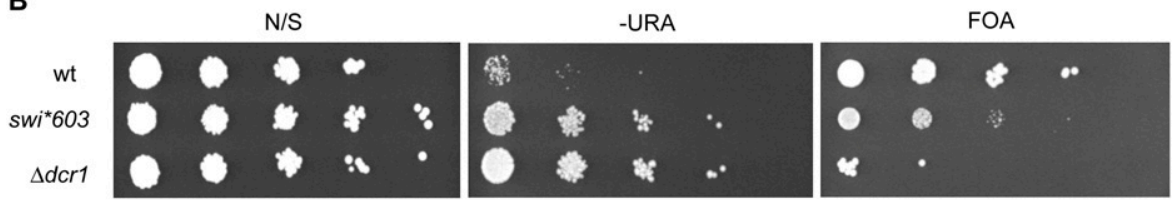

C

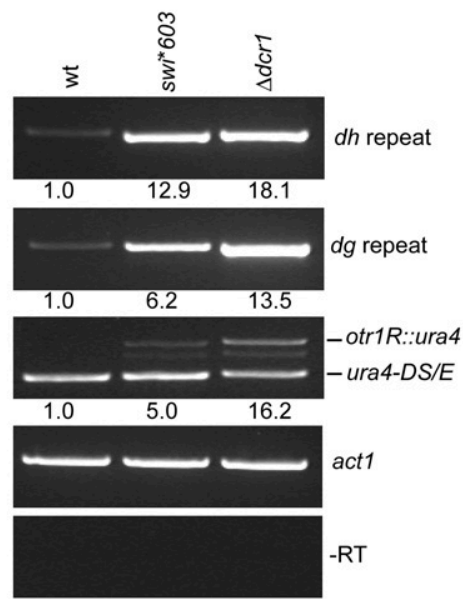

D

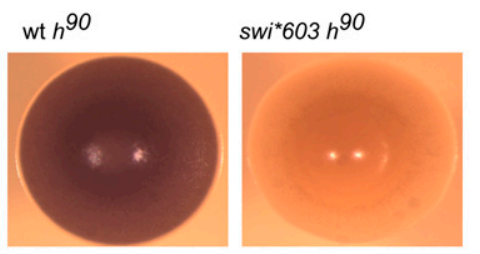

Figure 1. $s w{ }^{\star} 603$ is required for centromeric heterochromatin formation. (A) Cartoon of S. pombe centromere 1 . The central core domain, where the kintochore forms, is flanked by outer repeat domains composed of $d g$ and $d h$ repeat sequences. The position of the centromeric otr1R ::ura $4^{+}$reporter gene used in this study is indicated. (B) swi* 603 affects silencing of centromeric heterochromatin. Serial dilution (plating) assays were performed to measure the expression of the pericentromeric otr $1 R:: u r a 4^{+}$ reporter gene in wt, swi* 603 , and RNAi-defective $\Delta d c r 1$ deletion cells. Cells were serially diluted $1 / 10$ (starting with $1 \times 10^{4}$ cells) and spotted onto plates with no selection $(\mathrm{N} / \mathrm{S})$, plates lacking uracil (-URA), and counter-selective plates containing 5-fluoro-orotic acid (FOA). Yeast with an active $u r a 4^{+}$ gene convert FOA to fluorodeoxyuridine, which is toxic to cells. (C) swi ${ }^{\star} 603$ results in the accumulation of transcripts derived from heterochromatic $d g$ and $d h$ centromere repeats. RT-PCR was performed using total RNA isolated from indicated strains to measure the amount of transcript derived from $d g$ and $d h$ centromeric repeats. In each sample, enrichment of each primer pair was measured relative to the control primer pair act1. Centromeric otr $1 R:: u r a 4^{+}$expression was also analyzed and compared with the transcriptionally active but nonfunctional mini-gene ura4-DS/E at the $u r a 4^{+}$locus. $-R T$, minus reverse transcription. $(D) s w^{\star} 603$ affects mating-type switching. lodine staining phenotypes of homothallic $\left(h^{90}\right)$ wt strain SPG17 and $s w i^{*} 603$ strain. Strains were streaked onto sporulation medium and allowed to grow at $26^{\circ} \mathrm{C}$ for $5 \mathrm{~d}$ before staining with iodine vapors.

in a Dicer deletion strain $(\Delta d c r 1)$ defective in RNAi-induced heterochromatin assembly (Fig. 1B,C). Further, while wt $h^{90}$ colonies stained uniformly dark brown with iodine, mutant $h^{90}$ colonies did not stain, remaining pale yellow (Fig. 1D). As heterothallic mutant strains of opposite mating-type $\left(h^{-}\right.$and $\left.h^{+}\right)$could mate and sporulate efficiently (data not shown), this indicated a defect in mating-type switching rather than RNAi. We therefore designated the unmapped mutation $s w i^{\star} 603$.

$s w i^{\star} 603$ was generated using the mutagen $N$-methyl- $N^{\prime}$-nitro$\mathrm{N}$-nitrosoguanidine (MNG), which induces single nucleotide transitions (Lucchesi et al. 1986). Traditional mapping approaches in $S$. pombe are laborious and time consuming, so we undertook an alternative approach to genetic mapping based on whole-genome resequencing and mutation detection. The trz1-corrected $s w i^{\star} 603$ strain, DI36, was backcrossed twice to the same wt isolate
( $h^{-}$DG21 or $h^{+}$FY648) to generate $s w i^{*} 603$ strains DI201 and DI206, respectively (Fig. 2A). Illumina genomic DNA libraries were generated from DNA isolated from wt DG21 and the three strains that carried the $s w i^{*} 603$ allele. The libraries were sequenced on an Illumina Genome Analyzer to generate 43.3-fold sequence coverage of $s w i^{\star} 603$ strain DI36, 36.4-fold sequence coverage of wt DG21, 10.9-fold sequence coverage of $s w i^{\star} 603$ strain DI201, and 7.56-fold sequence coverage of $s w i i^{\star} 603$ strain DI206 (Fig. 2A). Sequences were aligned to the published Sanger sequencing assembly of reference strain $972 h^{-}$and analyzed for single base changes using MAQ (Mapping and Assembly with Qualities; Li et al. 2008). The Broad Institute has also recently resequenced wt strain $972 h^{-}$to $>200$-fold sequence coverage and found 193 sequence discrepancies with the Sanger assembly, consistent with the very high accuracy of the $14-\mathrm{Mb}$ reference sequence (Wood et al. 2002). Eighty-six of these discrepancies were single base changes (www.broad.mit.edu), which we included in our analysis.

We identified 194 single base changes in $s w i^{*} 603$ strain DI36 that were not in the Sanger reference. Seventy-three of these base changes were in DI36 alone, 52 shared with Broad $972 h^{-}$and wt DG21, 68 shared with wt DG21 alone, and one with Broad $972 h^{-}$alone (Fig. 2B). We expected the mutation causing $s w i^{\star} 603$ to be one of the 73 single base changes found in $s w i^{\star} 603$ strain DI36 alone (Table 1). Twenty-two of these single base changes were inherited in the backcross $s w i{ }^{\star} 603$ strain DI201 (Fig. 2A), of which 11 were in genes, four of them silent substitutions (Table 2). Co-segregation analysis between single base changes and the silencing defect were performed using PCR and sequencing/digest, and a G-to-A base substitution at position 222 within the $u b c 4$ gene (SPBC119.02) on chromosome II displayed 100\% segregation with the centromeric silencing defect in five tetrads examined (Fig. 3A), indicating close linkage with $s w i^{\star} 603$. None of the other single base changes were closely linked to $u b c 4$ and were eliminated from the analysis. The $u b c 4$ gene encodes a ubiquitinconjugating enzyme (Seino et al. 2003), and when expressed on a plasmid under the control of a medium-strength inducible promoter, nmt1, it complemented the loss of heterochromatic silencing in $u b c 4-G 48 D$ cells (Fig. 3B).

The mutant allele is denoted as $u b c 4-G 48 D$, as the base substitution causes an amino acid transition from a highly conserved glycine to aspartic acid at amino acid 48 of the protein (G48D) (Supplemental Fig. 2A). When the $u b c 4-G 48 D$ allele was regenerated in the heterothallic DG21 and homothallic SPG17 wt backgrounds (strains DI301 and DI304; Supplemental Table 2), the 
Mutation mapping by whole-genome resequencing

A

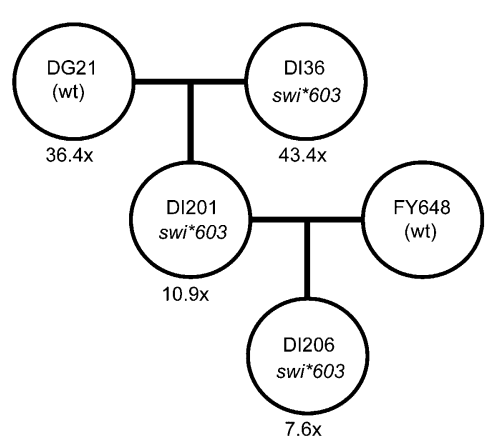

B

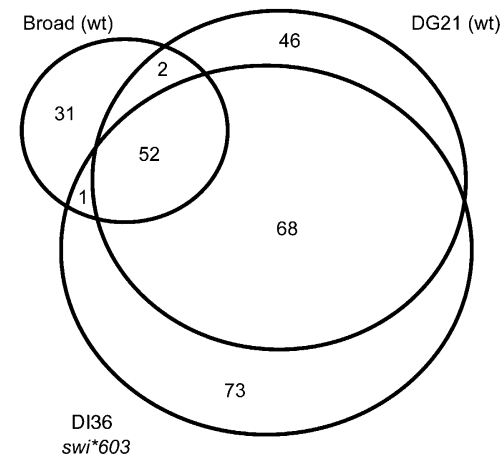

Figure 2. $s w i^{*} 603$ strain pedigree and single base changes detected. (A) swi*603 strain DI36 was backcrossed twice. The DI36 strain, our wt (DG21/FY648), and strains derived from the two crosses were sequenced to various degrees of coverage. (B) Single base changes identified by 200 fold resequencing of $972 h^{-}$by the Broad Institute, 36-fold sequencing of DG21 (wild type), and 43 -fold sequencing of swi* 603 strain DI36 were compared to identify 73 DI36-specific high-confidence single base changes potentially responsible for the observed phenotypes. In addition, divergences between wt DG21 and the recently sequenced $972 h^{-}$were identified relative to the cosmid library-derived wt reference sequence (Wood et al. 2002).

strains accumulated centromeric transcripts and failed to switch mating types, respectively (Fig. 3C,D). Further, when the $u b c 4$ $G 48 D$ allele was corrected in strain ts603 (strain DI302) the strain no longer accumulated centromeric transcripts (Supplemental Fig. $2 \mathrm{~B})$. Thus the $u b c 4-G 48 D$ allele was responsible for the centromeric silencing and the mating-type defects displayed by ts603. $u b c 4^{+}$ was recovered at a low frequency among the plasmids that suppressed the ts603 temperature sensitive phenotype, indicating it may also contribute to the ts603 growth phenotype on defined medium (Supplemental Table 1).

\section{Discussion}

Ubiquitin-conjugating enzymes, also known as E2 ligases, have diverse roles (Passmore and Barford 2004). Ubc4 is known to function with Ubc11 in the ubiquitination of mitotic cyclin Cdc13 by the APC/C (anaphase-promoting complex/cyclosome). Both ubiquitin-conjugating enzymes are directly required for the degradation of $\mathrm{Cdc} 13$ and the onset of the metaphase-anaphase transition (Seino et al. 2003), but this is unlikely to explain the silencing defect. Instead, the silencing defect in the $u b c 4-G 48 D$ strain resembles that of a cul4-1 mutant, which also exhibits loss of centromeric repeat silencing and mating-type switching defects
(Jia et al. 2005). Cul4 is a cullin family protein, found in the Clr4 histone methyltransferase complex (Petroski and Deshaies 2005). It is possible that Ubc4 is the E2 ligase in the Cul4-pathway. In support of this idea, $u b c 4^{+}$disrupts mitotic chromosome segregation when its cDNA is overexpressed (Javerzat et al. 1996), a phenotype shared with some silencing mutants.

Next-generation sequencing provides a powerful technology for mapping mutations in forward screens, and for identification of subsequent revertants. Importantly, genome sequencing immediately distinguishes complementing and suppressing genes recovered by library transformation, even in cases where true complementation is rare, and multiple mutations are found in each strain (Srivatsan et al. 2008). This is particularly powerful for mutations that revert spontaneously, such as those in epigenetic silencing pathways. In order to determine the coverage required for this approach we performed regression analysis on reads randomly sampled from the $s w i^{\star} 603$ DI36 library (Fig. 4). We found that all single base changes analyzed including $u b c 4-G 48 D$ were efficiently recovered with $98 \%$ confidence at $\sim 22$-fold coverage, using less than one Illumina flow cell (see Methods). The strategy can thus be summarized as follows: (1) sequence mutant strain to $20-25 \times$ coverage; (2) test candidate single base changes in backcross progeny until linked base change is found; (3) confirm by complementation. As the candidate single base changes include the mutation itself, no additional markers are required, allowing the use of monomorphic genomes such as $S$. pombe. Also because a candidate list is immediately accessible, new alleles in genes already known to result in the phenotype can be readily identified without further mapping.

The accuracy of next-generation sequencing is key to this approach and in the course of this study we uncovered about one in 100,000 nucleotide (nt) differences between lab isolates derived from the same strain. Nothing in our analysis indicated that any of these differences were due to miscalled bases, indicating these are real polymorphisms that have arisen since these strains were derived from a common, recent isolate. This raises the possibility that natural variation and environmentally induced variation could be readily examined with this approach. For example, wild strains could be grouped phenotypically for sequence analysis in bulk (bulk segregation analysis) to identify single base changes common to one but not another population. These methods are not unique to yeast genetics. Organisms with small well-characterized genomes, such as Arabidopsis, Caenorhabditis elegans, and Drosophila, lend themselves to this approach and would still only require a single flow cell of data to detect mutations by this method (Sarin et al. 2008; Srivatsan et al. 2008). The range of genomes to which this approach can be applied continues to increase along with the output of next-generation sequencing instruments. In early 2009 , resequencing a typical $S$. pombe mutant strain to $20-25 \times$ coverage costs less than $\$ 400$. One lane of a flow cell with paired $76 \mathrm{nt}$ reads and a high cluster density will yield $2.5 \mathrm{~Gb}$ of useful sequence, providing $\sim 180 \times$ coverage of the $S$. pombe $14-\mathrm{Mb}$ genome. By multiplexing and running several strains per lane the cost of resequencing a mutant strain is a fraction of the cost of a lane (\$2400-\$2800). The minimal cost and the high likelihood of identifying the causative mutation with 20-25-fold coverage suggest this method as the method of choice for single nucleotide mutation discovery in $S$. pombe. The use of paired end sequencing coupled with more advanced processing of the resulting data will also enable the identification of chromosomal rearrangements and small indels. Sequencing could thus realistically be applied to reverse genetic approaches, such as 
Irvine et al.

Table 1. Candidate single base changes in swi*603 strain DI36

\begin{tabular}{|c|c|c|c|c|c|}
\hline Chromosome & Position & Reference & Base change & $P$-value & Annotation (systematic name) \\
\hline 1 & 72347 & C & A & $8.00 \mathrm{E}-09$ & SPNCRNA. 83 \\
\hline 1 & 197811 & A & G & $5.00 \mathrm{E}-18$ & SPAC $13 G 6.12 \mathrm{C}$ \\
\hline 1 & 996210 & C & $\mathrm{T}$ & $3.00 \mathrm{E}-26$ & SPAC $821.08 c$ \\
\hline 1 & 1424707 & $\mathrm{C}$ & A & $6.00 \mathrm{E}-04$ & SPAC $3 A 12.04 \mathrm{C}$ \\
\hline 1 & 1709386 & G & A & $2.00 \mathrm{E}-17$ & SPAC 664.03 \\
\hline 1 & 1727519 & G & A & $3.00 \mathrm{E}-26$ & SPAC664.11 \\
\hline 1 & 1748591 & G & A & $6.00 \mathrm{E}-26$ & SPAC $105.03 c$ \\
\hline 1 & 2311516 & $\mathrm{C}$ & $\mathrm{T}$ & $2.00 \mathrm{E}-22$ & SPAC $13 G 7.08 c$ \\
\hline 1 & 2421577 & $\mathrm{C}$ & A & $5.00 \mathrm{E}-08$ & None \\
\hline 1 & 2440616 & G & A & $2.00 \mathrm{E}-18$ & SPAC6B12.15 \\
\hline 1 & 2667530 & A & $\mathrm{T}$ & $2.00 \mathrm{E}-04$ & None \\
\hline 1 & 2667913 & $\mathrm{~T}$ & A & $4.00 \mathrm{E}-05$ & None \\
\hline 1 & 2683904 & C & A & $1.00 \mathrm{E}-04$ & None \\
\hline 1 & 2727602 & G & A & $3.00 E-26$ & SPAC6F6.01 \\
\hline 1 & 3340816 & G & A & $3.00 E-26$ & SPAC26A3.05 \\
\hline 1 & 3548913 & $\mathrm{~T}$ & A & $1.00 \mathrm{E}-09$ & None \\
\hline 1 & 3633520 & G & A & $3.00 \mathrm{E}-26$ & SPAC1142.04 \\
\hline 1 & 3888360 & $\mathrm{C}$ & $\mathrm{T}$ & $3.00 E-26$ & None \\
\hline 1 & 3917000 & A & G & $4.00 \mathrm{E}-25$ & SPAC $323.06 c$ \\
\hline 1 & 3988549 & C & $\mathrm{T}$ & $1.00 \mathrm{E}-22$ & SPAPB15E9.01C \\
\hline 1 & 4037169 & C & $\mathrm{T}$ & $1.00 \mathrm{E}-24$ & SPAPJ698.02c \\
\hline 1 & 4236465 & $\mathrm{C}$ & $\mathrm{T}$ & $1.00 \mathrm{E}-21$ & SPAC1F7.08 \\
\hline 1 & 4407494 & $\mathrm{~T}$ & G & $2.00 \mathrm{E}-05$ & SPAC29E6.03c \\
\hline 1 & 4432687 & C & $\mathrm{T}$ & $6.00 \mathrm{E}-26$ & SPAC $16.05 c$ \\
\hline 1 & 4898837 & G & A & $2.00 \mathrm{E}-25$ & SPAC19B12.08 \\
\hline 1 & 4958832 & $\mathrm{C}$ & $\mathrm{T}$ & $5.00 \mathrm{E}-19$ & None \\
\hline 1 & 5129061 & G & A & $5.00 \mathrm{E}-22$ & None \\
\hline 1 & 5395830 & G & A & $3.00 \mathrm{E}-26$ & SPAC $3 G 6.09 c$ \\
\hline 2 & 36899 & A & G & $1.00 \mathrm{E}-10$ & None \\
\hline 2 & 36902 & $\mathrm{~T}$ & A & $8.00 \mathrm{E}-22$ & None \\
\hline 2 & 153849 & A & G & $2.00 \mathrm{E}-05$ & SPBC1683.07 \\
\hline 2 & 715554 & G & A & $3.00 \mathrm{E}-26$ & SPBC 119.02 \\
\hline 2 & 1079815 & G & A & $2.00 \mathrm{E}-08$ & None \\
\hline 2 & 1175944 & $\mathrm{~T}$ & C & $3.00 E-23$ & None \\
\hline 2 & 1272147 & G & A & $4.00 \mathrm{E}-20$ & SPBC3D6.03c \\
\hline 2 & 1287946 & $\mathrm{G}$ & A & $6.00 \mathrm{E}-24$ & SPBC 3D6.10 \\
\hline 2 & 1422317 & $\mathrm{~T}$ & A & $3.00 E-26$ & SPBC691.02c \\
\hline 2 & 1464936 & A & G & $5.00 \mathrm{E}-24$ & SPBC $32 \mathrm{H} 8.07$ \\
\hline 2 & 1535171 & G & $\mathrm{C}$ & $3.00 \mathrm{E}-19$ & SPBC $83.14 \mathrm{C}$ \\
\hline 2 & 1716288 & G & $\mathrm{T}$ & $4.00 \mathrm{E}-04$ & None \\
\hline 2 & 1861421 & G & $\mathrm{T}$ & $5.00 \mathrm{E}-06$ & None \\
\hline 2 & 1885317 & $\mathrm{C}$ & $\mathrm{T}$ & $3.00 E-26$ & SPBC $3 \mathrm{H} 7.02$ \\
\hline 2 & 1919015 & $\mathrm{C}$ & $\mathrm{T}$ & $3.00 \mathrm{E}-26$ & SPBC $16 E 9.02 C$ \\
\hline 2 & 1941967 & G & $\mathrm{T}$ & $6.00 \mathrm{E}-09$ & None \\
\hline 2 & 1941968 & A & G & $2.00 \mathrm{E}-07$ & None \\
\hline 2 & 1948954 & A & G & $3.00 \mathrm{E}-05$ & SPBC16E9.16C \\
\hline 2 & 1950053 & $\mathrm{~T}$ & G & $2.00 \mathrm{E}-06$ & SPBC16E9.16C \\
\hline 2 & 2007715 & A & G & $4.00 \mathrm{E}-24$ & None \\
\hline 2 & 2053516 & G & $\mathrm{C}$ & $8.00 \mathrm{E}-08$ & SPBC29A3.08 \\
\hline 2 & 2187407 & G & A & $6.00 \mathrm{E}-07$ & None \\
\hline 2 & 2561514 & G & A & $3.00 \mathrm{E}-26$ & SPBC29A10.10c \\
\hline 2 & 2574471 & $\mathrm{C}$ & $\mathrm{T}$ & $6.00 \mathrm{E}-14$ & None \\
\hline 2 & 2576463 & G & $\mathrm{T}$ & $4.00 \mathrm{E}-19$ & None \\
\hline 2 & 3232035 & $\mathrm{~T}$ & G & $1.00 \mathrm{E}-24$ & None \\
\hline 2 & 3619005 & $\mathrm{~T}$ & G & $3.00 \mathrm{E}-06$ & SPBC16D10.10 \\
\hline 2 & 3958740 & C & $\mathrm{T}$ & $3.00 \mathrm{E}-26$ & None \\
\hline 2 & 4074149 & G & A & $3.00 \mathrm{E}-23$ & SPBC1347.07 \\
\hline 2 & 4129016 & A & G & $5.00 \mathrm{E}-22$ & None \\
\hline 2 & 4254962 & A & $\mathrm{T}$ & $2.00 \mathrm{E}-04$ & None \\
\hline 3 & 298605 & C & $\mathrm{T}$ & $3.00 \mathrm{E}-21$ & None \\
\hline 3 & 474382 & $\mathrm{G}$ & A & $3.00 \mathrm{E}-26$ & None \\
\hline 3 & 595130 & $\mathrm{~T}$ & G & $1.00 \mathrm{E}-04$ & SPCC 1183.02 \\
\hline 3 & 679772 & $\mathrm{~T}$ & $\mathrm{C}$ & $2.00 \mathrm{E}-18$ & None \\
\hline 3 & 975830 & C & $\mathrm{T}$ & $3.00 \mathrm{E}-26$ & SPCC1795.11 \\
\hline 3 & 1028505 & $\mathrm{C}$ & T & $3.00 \mathrm{E}-26$ & SPCC $825.03 c$ \\
\hline 3 & 1097575 & $\mathrm{~T}$ & C & $2.00 \mathrm{E}-09$ & None \\
\hline 3 & 1442380 & $\mathrm{~T}$ & C & $3.00 \mathrm{E}-26$ & None \\
\hline 3 & 1450140 & C & $\mathrm{T}$ & $5.00 \mathrm{E}-20$ & SPCC61.05 \\
\hline 3 & 1587384 & G & A & $3.00 \mathrm{E}-25$ & SPCC $162.02 \mathrm{c}$ \\
\hline 3 & 1685492 & $\mathrm{C}$ & A & $1.00 \mathrm{E}-05$ & None \\
\hline 3 & 1721119 & A & $\mathrm{T}$ & $8.00 \mathrm{E}-04$ & None \\
\hline 3 & 1774237 & $\mathrm{~T}$ & A & $5.00 \mathrm{E}-04$ & SPCC $1442.04 \mathrm{C}$ \\
\hline 3 & 1989972 & C & T & $3.00 \mathrm{E}-23$ & SPCC18.18c \\
\hline
\end{tabular}


Mutation mapping by whole-genome resequencing

Table 2. Candidate single base changes in swi*603 strain DI201

\begin{tabular}{|c|c|c|c|c|c|c|}
\hline Chromosome & Position & Reference & Base change & $P$-value & Annotation (systematic name) & $\begin{array}{l}\text { Amino acid } \\
\text { change }\end{array}$ \\
\hline 1 & 72347 & C & A & $2.00 \mathrm{E}-05$ & SPNCRNA.83 & \\
\hline 1 & 4432687 & $\mathrm{C}$ & $\mathrm{T}$ & $2.00 E-19$ & SPAC $16.05 \mathrm{C}$ & A to $T$ \\
\hline 1 & 4958832 & C & $\mathrm{T}$ & $6.00 \mathrm{E}-10$ & None & \\
\hline 1 & 5129061 & G & A & $2.00 E-18$ & None & \\
\hline 1 & 5395830 & G & A & $6.00 \mathrm{E}-18$ & SPAC3G6.09c & $\mathrm{R}$ to $\mathrm{C}$ \\
\hline 2 & 36899 & A & G & $3.00 \mathrm{E}-10$ & None & \\
\hline 2 & 36902 & $\mathrm{~T}$ & A & $2.00 \mathrm{E}-20$ & None & \\
\hline 2 & 715554 & G & A & $3.00 \mathrm{E}-19$ & SPBC119.02 & $G$ to $D$ \\
\hline 2 & 1422317 & $\mathrm{~T}$ & A & $2.00 \mathrm{E}-16$ & SPBC691.02c & Silent \\
\hline 2 & 1885317 & C & $\mathrm{T}$ & $4.00 \mathrm{E}-14$ & SPBC $3 \mathrm{H} 7.02$ & $G$ to $D$ \\
\hline 2 & 1919015 & $\mathrm{C}$ & $\mathrm{T}$ & $3.00 E-25$ & SPBC16E9.02C & $\mathrm{D}$ to $\mathrm{N}$ \\
\hline 2 & 2007715 & A & G & $3.00 E-15$ & None & \\
\hline 2 & 2561514 & G & A & $5.00 \mathrm{E}-19$ & SPBC29A10.10c & Silent \\
\hline 2 & 2574471 & $\mathrm{C}$ & $\mathrm{T}$ & $1.00 \mathrm{E}-18$ & None & \\
\hline 2 & 2576463 & G & $\mathrm{T}$ & $6.00 \mathrm{E}-20$ & None & \\
\hline 3 & 679772 & $\mathrm{~T}$ & C & $3.00 \mathrm{E}-19$ & None & \\
\hline 3 & 975830 & C & $\mathrm{T}$ & $6.00 \mathrm{E}-08$ & SPCC1795.11 & $\mathrm{R}$ to $\mathrm{H}$ \\
\hline 3 & 1028505 & C & $\mathrm{T}$ & $8.00 \mathrm{E}-20$ & SPCC $825.03 c$ & Silent \\
\hline 3 & 1442380 & $\mathrm{~T}$ & C & $3.00 E-16$ & None & \\
\hline 3 & 1450140 & C & $\mathrm{T}$ & $3.00 \mathrm{E}-16$ & SPCC 61.05 & $P$ to $S$ \\
\hline 3 & 1989972 & C & $\mathrm{T}$ & $1.00 \mathrm{E}-16$ & SPCC18.18c & Silent \\
\hline
\end{tabular}

A

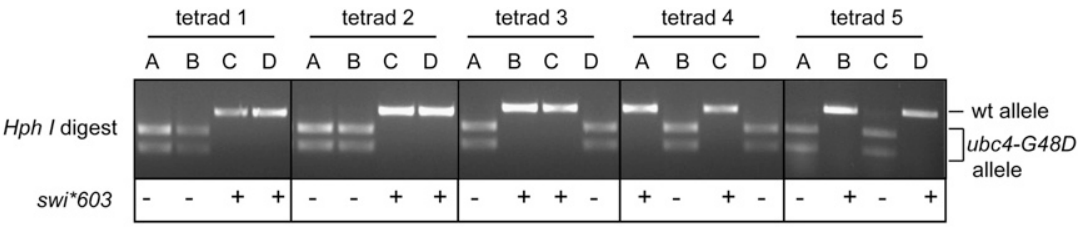

B

N/S
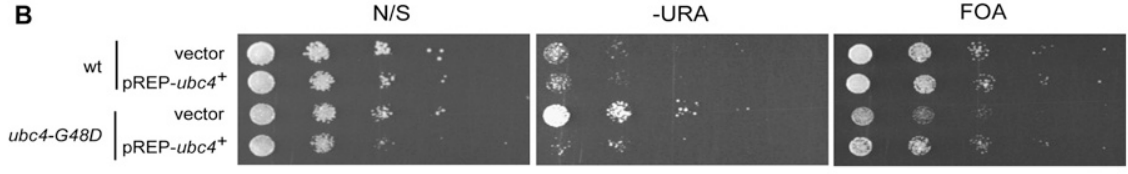

C

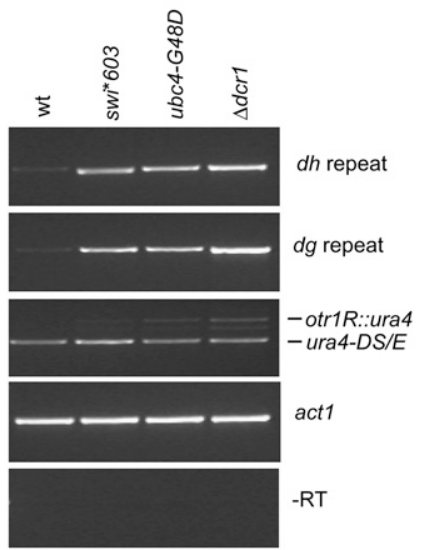

D

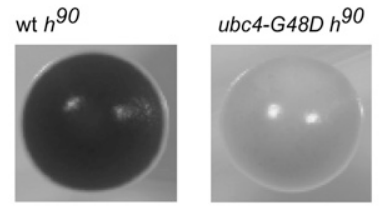

Figure 3. Verification that the $u b c 4-G 48 D$ mutation is responsible for $s w i^{\star} 603$ strain phenotypes. $(A)$ The ubc4-G48D mutant allele segregates $100 \%$ with the $s w i^{*} 603$ centromeric otr1R::ura $4^{+}$reporter gene loss of silencing phenotype. The ubc4-G48D allele is cut with Hphl to yield two bands, while

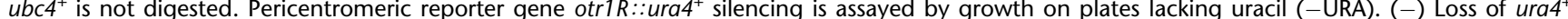
reporter gene silencing/growth on -URA plates/swi*603 allele; (+) silencing $u r a 4^{+}$reporter gene/no growth on -URA plates/wt. (B) The ubc4 $4^{+}$gene can complement the heterochromatic silencing defect in ubc4-G48D cells. Wild-type (wt) or ubc4-G48D cells were transformed with an empty G418-based plasmid or one expressing $u b c 4^{+}$under the control of an inducible medium-strength $n m t 1$ promoter. Serial dilution plating assays were performed (-thiamine) to measure the expression of the pericentromeric otr1R::ura $4^{+}$reporter gene. Cells were serially diluted $1 / 10$, starting with $1 \times 10^{4}$, and spotted onto nonselective plates (N/S), plates lacking uracil (-URA), and counter-selective plates containing 5-fluoro-orotic acid (FOA). (C) The ubc4G48D allele when introduced into wt DG21 causes accumulation of centromeric transcripts and the pericentromeric otr1R::ura $4^{+}$reporter gene. $(D)$ The iodine staining phenotypes of homothallic $\left(h^{90}\right)$ wt SGP17 and a regenerated ubc4-G48D strain show that the ubc4-G48D allele affects mating-type switching. 
A

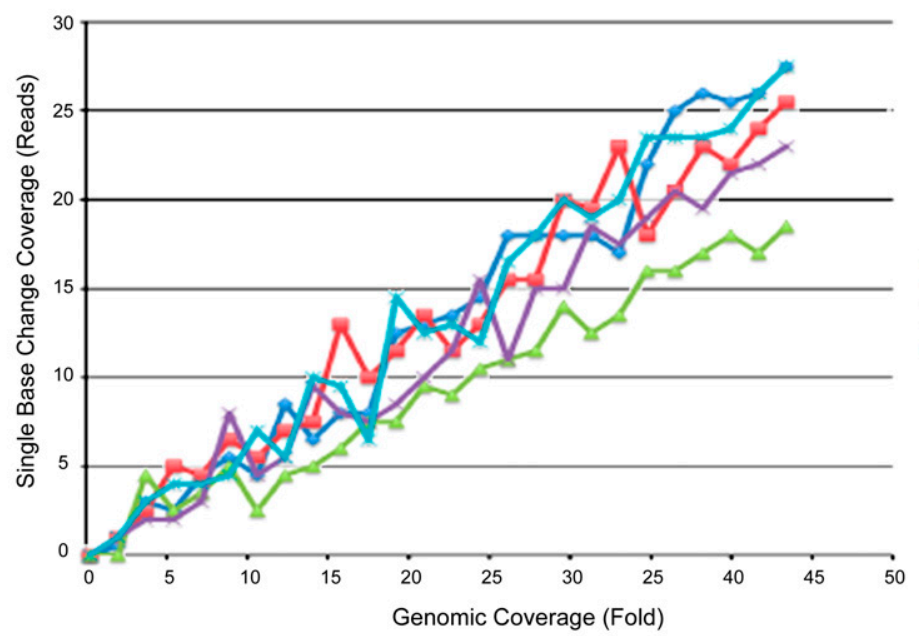

B

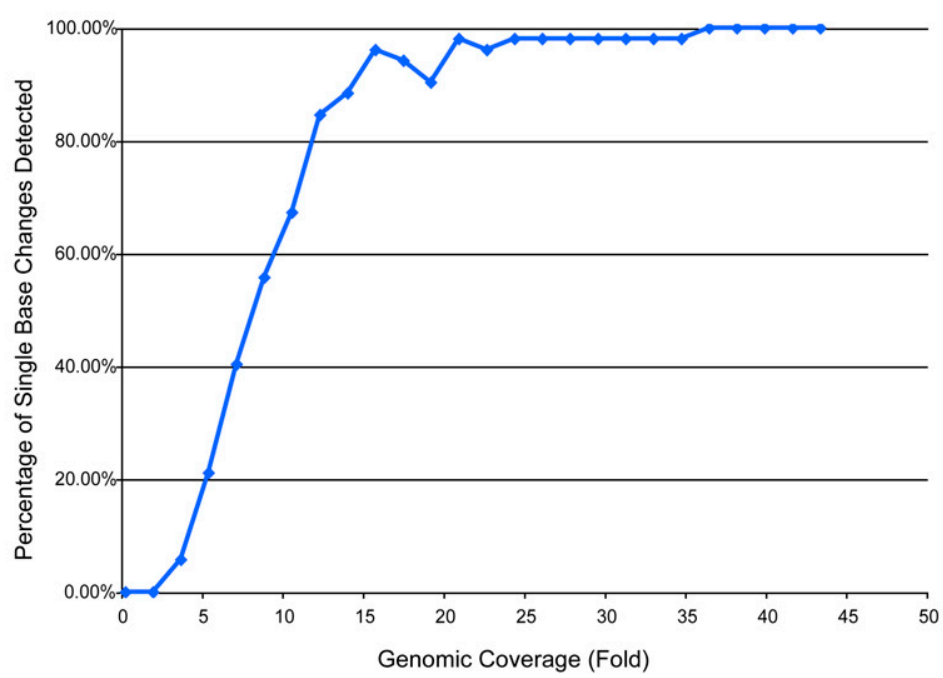

Figure 4. Relationship between library depth and single base change coverage. (A) The 17.04 million Solexa reads derived from $s w{ }^{\star} 603$ strain DI36 were sampled randomly to generate 25 libraries ranging from $0.25 \times$ to $43 \times$ coverage relative to the $S$. pombe reference genome. For each library, reads were aligned and single base changes detected using MAQ, and the number of sequences spanning five single base changes (including ubc4-G48D) was determined. The relationship between library depth and single base change coverage is generally linear but coverage can range from 1.5- to twofold at a given single base change, presumably due to localized differences in sequencing efficiency. $(B)$ The relationship between DI36 library depth and the percentage confidence of finding all 52 single base changes shared between Broad $972 h^{-}$, wt DG21, and swi*603 strain DI36. Approximately $22 \times$ coverage is required to get to $98 \%$ confidence of finding all 52 single base changes.

TILLING, in which a population of chemically mutagenized plants (or yeast) is interrogated for mutations in known genes (McCallum et al. 2000).

On the basis of our results we propose a comprehensive screen to identify gene networks essential for growth in fission yeast. Using genome sequencing, we were able to determine which of the 10 or more genes that rescued a ts lethal strain was responsible for the mutation. By sequencing each of the 1000 ts lethal strains in this collection (Matsumura et al. 2003; Hayashi et al. 2004; Yuasa et al. 2004), the causative mutation underlying each strain will be revealed, identifying the other rescuing plasmids as allele-specific suppressors. This will rapidly lead to a genetic network of genes essential for growth, complementing more traditional and laborious approaches such as epistasis mapping (Roguev et al. 2008).

\section{Methods}

\section{Strains and media}

S. pombe strains used in this study are listed in Supplemental Table 2. Yeast cells were cultured in supplemented yeast extract (rich) adenine (YEA) medium. Minimal medium with ammonium chloride as a nitrogen source (EMM2) was used in complementation studies. Crosses and mating-type switching were performed with malt extract plus amino acids (ME+AA) medium. $250 \mu \mathrm{g} / \mathrm{mL}$ of each supplement was added to media to support full growth. $100 \mu \mathrm{g} / \mathrm{mL}$ of G418 was used in YEA to select KanMX6 positive clones. Serial dilution experiments were performed as described previously (Ekwall et al. 1999).

\section{Genetic techniques}

To mutagenize the trz1 gene a targeting vector containing the trz1- $A 623 \mathrm{~V}$ allele was transformed into wt DG21. The targeting vector constructed in pBlueScript$\mathrm{KS}^{+}$consisted of a 2334-nt PCR fragment containing the coding region of trz1 plus some 3' untranslated sequence. The QuickChange II site-directed mutagenesis kit (Stratagene) allowed the introduction of the alanine 623 to valine (A623V) mutation into the coding sequence of trz1. A KanMX resistance gene was cloned into an NheI site $3^{\prime}$ of the stop codon. To correct the trz1-A623V allele in ts603 the same targeting vector containing trz1 $1^{+}$was transformed into ts603. To mutagenize the $u b c 4^{+}$gene a targeting vector containing the $u b c 4-G 48 D$ allele was transformed in wt strains DG21 and SPG17. The targeting vector constructed in pGEM-T (Promega) contained a 1563-nt PCR fragment containing the coding region of the $u b c 4-G 48 D$ allele amplified from ts603 and some $3^{\prime}$ untranslated sequence. The KanMX6 resistance gene was cloned into a SnaBI site $3^{\prime}$ of the stop codon. To correct the $u b c 4-G 48 D$ allele in ts603 a targeting vector containing $u b c 4^{+}$was constructed as described above. All plasmid DNA was linearized and transformed as described in Krawchuk and Wahls (1999). Transformants were confirmed for site-specific recombination by PCR, the presence of the mutant or wt allele by a combined PCR/HphI digest, and the integrity of the remaining coding sequence by Sanger sequencing.

\section{RNA analysis}

Total RNA was extracted from cells growing at exponential phase in YEA using RiboPure Yeast (Ambion). RNA was treated with $8 \mathrm{U}$ of

\section{Genome Research www.genome.org}


DNase I (DNA-free, Ambion) and analyzed by RT-PCR (One-Step RTPCR Kit, Qiagen). Cycles of PCR for $d g$ repeat, $d h$ repeat, centromeric $\mathrm{ura}^{+}{ }^{+}$reporter gene, and actin control were 28 cycles. Amplified DNA was separated in $2.0 \%$ agarose gels, stained with ethidium bromide, and visualized by Fluor-S Multimager (Bio-Rad).

\section{Whole-genome resequencing and single base change discovery}

Genomic DNA libraries for Illumina sequencing were prepared according to the manufacture's instructions. Libraries were sequenced on an Illumina Genome Analyzer. The resulting 32-36bp sequence reads, including quality scores, were aligned to the $S$. pombe reference sequence using MAQ (Li et al. 2008) using the "map" function. A consensus genome was built using MAQ "assemble" using only sequence reads with a phred-scaled alignment quality of 30 or better. Single base changes were detected using the MAQ "cns2snp" function. Single base changes with phred-scaled quality scores $<60$ or with fewer than six reads covering them were discarded. Single base changes found in this study are listed in Supplemental Tables 3-6.

\section{Acknowledgments}

D.V.I. is a C.J. Martin postdoctoral fellow and D.B.G. was a U.S. Department of Energy-Biosciences postdoctoral fellow of the Life Sciences Research Foundation. Research in the authors' laboratory is supported by a grant from NIH to R.M. (RO1-GM076396).

\section{References}

Allshire, R.C., Nimmo, E.R., Ekwall, K., Javerzat, J.P. and Cranston, G. 1995 Mutations derepressing silent centromeric domains in fission yeast disrupt chromosome segregation. Genes \& Dev. 9: 218-233.

Ekwall, K., Cranston, G., and Allshire, R.C. 1999. Fission yeast mutants that alleviate transcriptional silencing in centromeric flanking repeats and disrupt chromosome segregation. Genetics 153: 1153-1169.

Grewal, S.I. and Jia, S. 2007. Heterochromatin revisited. Nat. Rev. Genet. 8: 35-46.

Hayashi, T., Fujita, Y., Iwasaki, O., Adachi, Y., Takahashi, K., and Yanagida, M. 2004. Mis16 and Mis18 are required for CENP-A loading and histone deacetylation at centromeres. Cell 118: 715-729.

Hillier, L.W., Marth, G.T., Quinlan, A.R., Dooling, D., Fewell, G., Barnett, D., Fox, P., Glasscock, J.I., Hickenbotham, M., Huang, W., et al. 2008. Whole-genome sequencing and variant discovery in C. elegans. Nat. Methods 5: 183-188.

Javerzat, J.P., Cranston, G., and Allshire, R.C. 1996. Fission yeast genes which disrupt mitotic chromosome segregation when overexpressed. Nucleic Acids Res. 24: 4676-4683.

Jia, S., Kobayashi, R., and Grewal, S.I. 2005. Ubiquitin ligase component Cul4 associates with Clr4 histone methyltransferase to assemble heterochromatin. Nat. Cell Biol. 7: 1007-1013.
Kato, H., Goto, D.B., Martienssen, R.A., Urano, T., Furukawa, K., and Murakami, Y. 2005. RNA polymerase II is required for RNAi-dependent heterochromatin assembly. Science 309: 467-469.

Krawchuk, M.D. and Wahls, W.P. 1999. High-efficiency gene targeting in Schizosaccharomyces pombe using a modular, PCR-based approach with long tracts of flanking homology. Yeast 15: 1419-1427.

Li, F., Goto, D.B., Zaratiegui, M., Tang, X., Martienssen, R., and Cande, W.Z. 2005. Two novel proteins, dos1 and dos2, interact with rik1 to regulate heterochromatic RNA interference and histone modification. Curr. Biol. 15: $1448-1457$.

Li, H., Ruan, J., and Durbin, R. 2008. Mapping short DNA sequencing reads and calling variants using mapping quality scores. Genome Res. 18: 1851-1858.

Lucchesi, P., Carraway, M., and Marinus, M.G. 1986. Analysis of forward mutations induced by $N$-methyl- $N^{\prime}$-nitro- $N$-nitrosoguanidine in the bacteriophage P22 mnt repressor gene. J. Bacteriol. 166: 34-37.

Mardis, E.R. 2008. The impact of next-generation sequencing technology on genetics. Trends Genet. 24: 133-141.

Matsumura, T., Yuasa, T., Hayashi, T., Obara, T., Kimata, Y., and Yanagida, M. 2003. A brute force postgenome approach to identify temperaturesensitive mutations that negatively interact with separase and securin plasmids. Genes Cells 8: 341-355.

McCallum, C.M., Comai, L., Greene, E.A., and Henikoff, S. 2000. Targeting induced local lesions IN genomes (TILLING) for plant functional genomics. Plant Physiol. 123: 439-442.

Moreno, S., Klar, A., and Nurse, P. 1991. Molecular genetic analysis of fission yeast Schizosaccharomyces pombe. Methods Enzymol. 1994: 795-823.

Passmore, L.A. and Barford, D. 2004. Getting into position: The catalytic mechanisms of protein ubiquitylation. Biochem. J. 379: 513-525.

Petroski, M.D. and Deshaies, R.J. 2005. Function and regulation of cullinRING ubiquitin ligases. Nat. Rev. Mol. Cell Biol. 6: 9-20.

Roguev, A., Bandyopadhyay, S., Zofall, M., Zhang, K., Fischer, T., Collins, S.R., Qu, H., Shales, M., Park, H.O., Hayles, J., et al. 2008. Conservation and rewiring of functional modules revealed by an epistasis map in fission yeast. Science 322: $405-410$.

Sarin, S., Prabhu, S., O'Meara, M.M., Pe'er, I., and Hobert, O. 2008. Caenorhabditis elegans mutant allele identification by whole-genome sequencing. Nat. Methods 5: 865-867.

Seino, H., Kishi, T., Nishitani, H., and Yamao, F. 2003. Two ubiquitinconjugating enzymes, UbcP1/Ubc4 and UbcP4/Ubc11, have distinct functions for ubiquitination of mitotic cyclin. Mol. Cell. Biol. 23: 34973505.

Srivatsan, A., Han, Y., Peng, J., Tehranchi, A.K., Gibbs, R., Wang, J.D., and Chen, R. 2008. High-precision, whole-genome sequencing of laboratory strains facilitates genetic studies. PLoS Genet. 4: e1000139. doi: 10.1371/ journal.pgen.1000139.

Wood, V.R., Gwilliam, M.A., Rajandream, M., Lyne, R., Lyne, A., Stewart, J., Sgouros, N., Peat, J., Hayles, S., Baker, D., et al. 2002. The genome sequence of Schizosaccharomyces pombe. Nature 415: 871-880.

Yuasa, T., Hayashi, T., Ikai, N., Katayama, T., Aoki, K., Obara, T., Toyoda, Y., Maruyama, T., Kitagawa, D., Takahashi, K., et al. 2004. An interactive gene network for securin-separase, condensin, cohesin, Dis1/Mtc1 and histones constructed by mass transformation. Genes Cells 9: 1069_ 1082.

Zaratiegui, M., Irvine, D.V., and Martienssen, R.A. 2007. Noncoding RNAs and gene silencing. Cell 128: 763-776.

Received December 17, 2008; accepted in revised form April 2, 2009. 


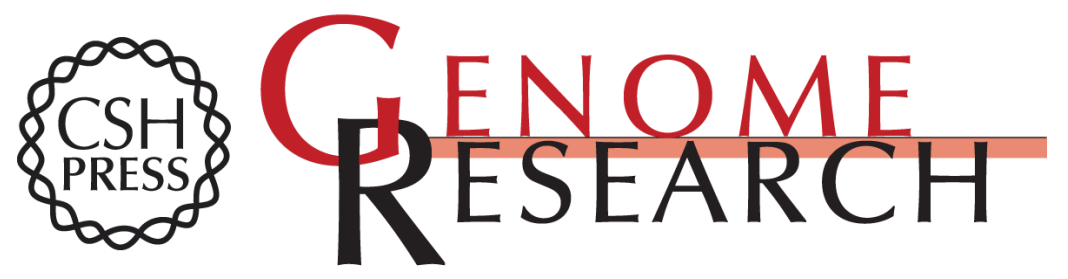

\section{Mapping epigenetic mutations in fission yeast using whole-genome next-generation sequencing}

Danielle V. Irvine, Derek B. Goto, Matthew W. Vaughn, et al.

Genome Res. 2009 19: 1077-1083 originally published online May 7, 2009

Access the most recent version at doi:10.1101/gr.089318.108

Supplemental Material

References

License

Email Alerting Service
http://genome.cshlp.org/content/suppl/2009/05/08/gr.089318.108.DC1

This article cites 25 articles, 8 of which can be accessed free at: http://genome.cshlp.org/content/19/6/1077.full.html\#ref-list-1

Receive free email alerts when new articles cite this article - sign up in the box at the top right corner of the article or click here.

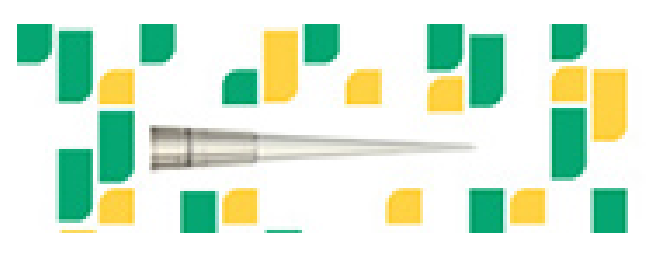

Focused on your science.

J⿹勹ి

SCIENTIFIC

suos or seisnes

To subscribe to Genome Research go to: https://genome.cshlp.org/subscriptions 